\title{
Limb pain in migraine and cluster headache
}

\author{
R J GUILOFF, M FRUNS*
}

From the Department of Neurology, Westminster Hospital, Charing Cross and Westminster Medical School, London, UK

SUMMARY Upper limb pain occurred in close temporal association with attacks of migraine, cluster headache and cluster-migraine in 22 cases. Seven had also lower limb pain. Limb pain was usually ipsilateral to the headache but could alternate sides and behaved like other accepted migraine accompaniments. It was always ipsilateral to the associated paraesthesiae/numbness ( 9 cases) and weakness (6 cases). The distribution and restricted localisations of limb pain were similar to those of the sensory symptoms and could not be accounted for by primary dysfunction of the peripheral or autonomic nervous systems. A central origin for limb pain is postulated. A temporary dysfunction in the somatosensory cortex, and/or its thalamic connections, during migraine or cluster headache attacks, might mediate such pain in a number of patients.

"The particular form and character of the paroxysm will be determined chiefly by the extent and anatomical localisation of the disturbance in each case ..."

(Liveing, 1873)

Liveing referred to upper and lower limb pain in association with paraesthesiae in migraine. ${ }^{1}$ Gowers stated that migraine pain may radiate from the side of the head to the neck and arm. ${ }^{2}$ Jeliffe described a patient with right sided migraine and ipsilateral pain and numbness in the arm and numbness and weakness in the leg. ${ }^{3}$ Other cases with upper limb pain were reported by Sluder, ${ }^{4-8}$ Cushing, ${ }^{9}$ Harris, ${ }^{10}$ Vaill, ${ }^{11} 12$ Glaser, ${ }^{13}$ Frazier, ${ }^{14}$ and Brunelli. ${ }^{15}$ Cases with pain in the lower limb were reported by Gowers, ${ }^{2}$ Sluder, ${ }^{5}$ and Brunelli. ${ }^{15}$

There are few reports in the more recent literature. Montgomery and $\mathrm{King}^{16}$ described a case of hemiplegic migraine with paroxysmal shoulder-hand syndrome. Wolff accepted radiation to the arm in "cephalalgias and atypical neuralgias of the face and head", regarded the mechanisms of pain as similar to migraine and stated that it could be improved by ergotamine tartrate. ${ }^{17}$ Sacks described a woman with episodes of migraine and pain in the hands. ${ }^{18}$ Sutherland and Eadie referred to extension of pain to the ipsilateral arm in a case of cluster headache. ${ }^{19}$

Address for reprint requests: Dr R J Guiloff, Westminster Hospital, 17 Page Street, London SWIP 2AP, UK

*British Council Scholar. Present address: Institute of Neurology, Queen Square, London WCIN 3BG, UK.

Received 25 August 1987 and in revised form 26 January 1988. Accepted 11 April 1988
Wakefield reported a patient with migraine and pain and weakness in the leg. ${ }^{20}$ Radiation of chest pain to the arm has been described in "precordial or cardiac migraine". ${ }^{21}$ Sjaastad and Dale reported spread to the ipsilateral shoulder and arms in patients with "chronic paroxysmal hemicrania". 2223 Olesen et al. referred to a patient with migraine and unexplained attacks of upper limb pain. ${ }^{24}$

Weakness or visual and sensory phenomena are accepted focal symptoms of migraine but limb pain is not included in standard descriptions. ${ }^{25-28}$ Since upper limb pain in "cervical migraine" was interpreted as secondary to cervical spine trauma, ${ }^{29}{ }^{30}$ no critical analysis of a series of such cases has been reported, nor has the pain mechanism been considered in terms of recent anatomical and physiological data.

We report 22 cases with unilateral, sometimes alternating, limb pain as a prominent complaint associated with "vascular headache of migraine type". ${ }^{31}$ The features of the pain and its temporal relationship with the headache suggest that it is either part of the headache episode or that it behaves like other accepted accompaniments of "migrainous headache". Limb pain does not respect current classification boundaries $^{32}$ and has been seen in association with common and classical migraine, cluster headache and cluster-migraine. The complaint is benign and has occurred over many years without sequelae. A central origin for limb pain and implications for the mechanism of the headache will also be discussed.

\section{Methods and material}

The diagnosis of migraine and related "vascular" headaches 
is clinical. When relating a particular symptom to the condition, it is necessary to describe cases of headache acceptable to many neurologists as examples of migraine, cluster headache and cluster-migraine and to show that a pattern of association between the headache and that symptom exists, in the absence of other detectable known mechanisms or causes for it.

Patients were selected prospectively from all new patients referred to, and examined by, the same neurologist (RJG), by the coexistence of limb pain and headache with a temporal profile suggestive of an association between the two (see below). When accepting a diagnosis of migraine, cluster ${ }^{n}$ headache or cluster-migraine, the features of the headache and associated symptoms, excluding limb pain, were considered (see below).

The headache fitted the definitions of migraine proposed b. the Ad Hoc Committee for the Classification of - Geadaches ${ }^{31}$ and by Lance ${ }^{27}$ or that of cluster headache proposed by the Research Group on Headache of the World Federation of Neurology. ${ }^{33}$ We accepted cluster attacks lasting longer than 2 hours as, in our experience, this may occur. Others have described single attacks lasting 1-2 days. ${ }^{19} 34$ Classical migraine is used as in Rose's classification. ${ }^{32}$ including focal visual, motor and sensory symptoms and basilar migraine. Cluster-migraine ${ }^{35}$ is used for cluster headache associated with paraesthesiae, weakness, visual phenomena or because the headache could be bilateral. Classification of headache was made for those that had occurred previously, and for those at presentation and during follow-up, with and without limb pain (table 1).

A temporal profile suggestive of an association between headache and limb pain was defined as the occurrence of one or more episodes of such pain immediately preceding or following the onset of headache, present during it, or shortly after it. Good evidence of response to a drug was judged from recurrence on drug withdrawal or reduction in dose. Partial response was scored when chance or placebo effect could not be excluded.

Twenty-two consecutive cases were collected between 1 January 1983 and 30 June 1986. They were seen at two central London teaching hospitals serving a local population of 125,000 , as well as commuters and specialist referrals. Thirteen lived locally, nine outside the district. There were 19 females and three males. One patient was lost to follow-up. In the remainder, median follow up was 9 months; 10 cases $(47 \%)$ were followed for one or more years (table 1).

\section{Results}

Most patients with limb pain were female. young and had a form of headache currently classifiable as either cluster-migraine or cluster headache. Limb pain also occurred in association with common and classical migraine and in males or elderly patients. Headache with limb pain was often different in type to headaches experienced in the past, but once established, in most cases, it remained of the same type during the period of observation, even when it occurred without limb pain. Limb pain, often a prominent complaint, always affected the upper limb and sometimes the lower limb, was usually ipsilateral to the headache and could also alternate between sides. It started either with or following the headache, but could also occur independently, in isolation. Paraesthesiae and/or numbness and/or weakness were often associated ipsilaterally to both limb pain and headache. The commonest triggering or exacerbating factor for limb pain was limb use or movement. Table 1 summarises all cases. Illustrative cases are described below.

\section{Analysis of clinical data}

Limb pain. Limb or body pain was the main, or a prominent, complaint in 20 cases and one, or the only, reason for referral in 16 . It did not precede the headache in any case and was concomitant with the latter in 15 patients. Six cases timed limb pain to a "few minutes", $5 \mathrm{~min}, 30 \mathrm{~min}, 1 \mathrm{~h}$ and $2 \mathrm{~h}$ after the onset of headache. Limb pain started after the headache episode in 1 case.

Case 1 Common migraine and concomitant neck and arm pain. A 19 year old girl presented with a 1 month history of frequent episodes of throbbing pain in the left temple, above the left ear, left side of the neck and left arm, lasting a few hours and sometimes associated with nausea. She had been on a contraceptive pill for 7 months. A sister had headaches. Following propanolol she reported a reduction in the frequency of her headaches.

Isolated independent episodes of limb or body pain were reported by 11 patients. In nine of them the pain affected the same part of the limb to the one involved during a headache episode. One reported pain in the fingers with headache and pain in the ulnar side of the forearm and dorsum of the wrist in isolation. Another had pain in the shoulder with headache and pain in the ventral aspect of the wrist in isolation.

Case 13 Cluster headache with associated or isolated ipsilateral chest and upper and lower limb pain. This 54 year old woman had had episodes of left-sided throbbing headache and throbbing pain in the left side of the chest radiating to the left shoulder and arm and left hip and thigh lasting $1-3 \mathrm{~h}$ for at least $10 \mathrm{yr}$. They occurred daily in bouts lasting about $6 \mathrm{wk}$ with pain free intervals of up to $2 \mathrm{wk}$. A recent bout had lasted for 3 months. Often they were associated with a feeling of a blocked nose. On occasions there was only chest and limb pain during the bout, but when she had headache she had also chest and limb pain for the same period of time. She improved on propranolol $20 \mathrm{mg}$ thrice daily.

The localisation of limb and body pain in each patient is shown in table 1 . In the upper limb the part most often affected was the arm $(n=18)$. The shoulder was affected in nine patients, the axilla in two, the forearm in six, the wrist in five and the hand in five. The leg was affected in six cases and thigh, knee and foot in two each. Other pain occurring independently of limb pain was reported by two cases with facial pain, two with neck pain, and one with chest 
Table 1 Main features of patients with headache associated with limb pain

\begin{tabular}{|c|c|c|c|c|c|c|c|c|c|c|c|c|c|c|c|}
\hline \multicolumn{4}{|c|}{ Patients } & \multicolumn{3}{|c|}{$\begin{array}{l}\text { Headache } \\
\text { past present }\end{array}$} & \multicolumn{2}{|c|}{ follow up } & \multirow{2}{*}{$\begin{array}{l}\begin{array}{l}\text { Other } \\
\text { pain }\end{array} \\
\text { location }\end{array}$} & \multicolumn{3}{|l|}{ Duration } & \multicolumn{2}{|l|}{ Focal symptoms } & \multirow{2}{*}{$\begin{array}{l}\text { Treatment } \\
\begin{array}{l}\text { drug and } \\
\text { effect }\end{array}\end{array}$} \\
\hline No & $\begin{array}{l}\text { Age } \\
(y r)\end{array}$ & Sex & $F H$ & & $\begin{array}{l}\operatorname{limb} \\
\text { pain }\end{array}$ & $\begin{array}{l}\text { No } \\
\operatorname{limb} \\
\text { pain }\end{array}$ & $\underset{\text { pain }}{\operatorname{limb}}$ & $\begin{array}{l}\text { No } \\
\text { limb } \\
\text { pain }\end{array}$ & & headache & pain & $\begin{array}{l}\text { follow } \\
\text { up }\end{array}$ & $\begin{array}{l}\text { Numbness/ } \\
\text { paraesthesia } \\
\text { location }\end{array}$ & $\begin{array}{l}\text { weakness } \\
\text { location }\end{array}$ & \\
\hline $\begin{array}{l}1 \\
2 \\
3\end{array}$ & $\begin{array}{l}19 \\
37 \\
32\end{array}$ & $\begin{array}{l}F \\
F\end{array}$ & $\begin{array}{l}+ \\
+ \\
+\end{array}$ & $\begin{array}{l}\overline{\mathrm{CH}} \\
\mathrm{CM}\end{array}$ & $\begin{array}{l}\mathrm{CM} \\
\mathrm{CH} \\
\mathrm{CH}-\mathrm{M}\end{array}$ & $\begin{array}{l}\overline{\mathrm{CH}} \\
\mathrm{CH}-\mathrm{M}\end{array}$ & $\frac{\mathrm{CM}}{\overline{\mathrm{CH}}-\mathrm{M}}$ & $\overline{\overline{C M}}$ & $\begin{array}{l}\text { N,UL } \\
\text { F,UL, LL } \\
\text { F, UL, LL }\end{array}$ & $\begin{array}{l}1 \mathrm{~m} \\
28 \mathrm{y} \\
20 \mathrm{y}\end{array}$ & $\underset{1 \mathrm{y}}{28 \mathrm{~m}}$ & $\begin{array}{l}2 \mathrm{~m} \\
0 \\
3 \mathrm{y} 6 \mathrm{~m}\end{array}$ & F, UL, LL & & $\begin{array}{l}\text { Par }^{+++} \text {Prop }^{+} \\
\text {Prop }^{+}\end{array}$ \\
\hline $\begin{array}{l}4 \\
5\end{array}$ & $\begin{array}{l}24 \\
52\end{array}$ & $\begin{array}{l}\mathbf{F} \\
\mathbf{M}\end{array}$ & & $\overline{\mathrm{ClM}}$ & $\begin{array}{l}\text { CH-M } \\
\text { CH-M } \\
\text { CH }\end{array}$ & $\overline{\mathrm{CH}}$ & $\underline{-}$ & $\overline{\mathrm{CH}}$ & $\begin{array}{l}\text { N, UL } \\
\text { F, N, UL, LL }\end{array}$ & $\begin{array}{l}4 \mathrm{~m} \\
12 \mathrm{y}\end{array}$ & $\begin{array}{l}4 \mathrm{~m} \\
3 \mathrm{~m}\end{array}$ & $\begin{array}{l}4 \mathrm{~m} \\
1 \mathrm{y} 2 \mathrm{~m}\end{array}$ & F, UL & UL, LL & $\begin{array}{l}\text { Prop } \\
\text { Piz }\end{array}$ \\
\hline $\begin{array}{l}6 \\
7\end{array}$ & $\begin{array}{l}41 \\
32\end{array}$ & $\begin{array}{l}\mathbf{F} \\
\mathbf{F}\end{array}$ & & $\begin{array}{l}\mathrm{CM} \\
\mathrm{ClM}\end{array}$ & $\underset{\mathrm{CH}}{\mathrm{ClM}}$ & $\underline{\mathrm{ClM}}$ & $\overline{\mathrm{CH}}$ & $\overline{\mathrm{CM}}$ & $\begin{array}{l}\text { F, UL } \\
\text { UL, C }\end{array}$ & $\begin{array}{l}31 y \\
17 y\end{array}$ & $\operatorname{lm}_{\mathrm{ly}}$ & $\begin{array}{l}2 \mathrm{~m} \\
1 \mathrm{y} 2 \mathrm{~m}\end{array}$ & F, UL, LL & UL, LL & $\begin{array}{l}\text { Prop }^{+} \\
\text {Prop }^{+} \text {Piz }^{+} \\
\text {Ergot } 0\end{array}$ \\
\hline $\begin{array}{l}8 \\
9\end{array}$ & $\begin{array}{l}26 \\
25\end{array}$ & $\begin{array}{l}\mathbf{F} \\
\mathbf{F}\end{array}$ & + & $\overline{\mathrm{ClM}}$ & $\begin{array}{l}\mathrm{CM}^{*} \\
\mathrm{ClM}\end{array}$ & $\overline{\mathrm{ClM}}$ & $\underline{\mathrm{CM}}$ & $\underline{\mathrm{CM}}$ & $\begin{array}{l}\text { F, UL, LL } \\
\text { N, UL }\end{array}$ & $\begin{array}{l}3 \mathrm{~m} \\
13 \mathrm{y}\end{array}$ & $\begin{array}{l}3 \mathrm{~m} \\
6 \mathrm{y}\end{array}$ & $\begin{array}{l}1 \mathrm{y} 10 \mathrm{~m} \\
4 \mathrm{~m}\end{array}$ & $n_{\text {UL }}$ & UL & $\begin{array}{l}\text { Prop 0 } \\
\text { Prop }^{++} \\
\text {Ergot }^{++}\end{array}$ \\
\hline $\begin{array}{l}10 \\
11\end{array}$ & $\begin{array}{l}38 \\
33\end{array}$ & $\begin{array}{l}\mathbf{M} \\
\mathbf{M}\end{array}$ & & $\begin{array}{l}\mathrm{CH}-\mathrm{M} \\
\mathrm{CM}\end{array}$ & $\begin{array}{l}\text { I CH-M } \\
\text { CH-M }\end{array}$ & - & $\begin{array}{l}\text { CH-M } \\
\text { CH-M }\end{array}$ & 二 & $\begin{array}{l}\text { N, UL } \\
\text { N, UL }\end{array}$ & $\begin{array}{r}4 y \\
22 y\end{array}$ & $1 \mathrm{~m}$ & $\begin{array}{l}9 \mathrm{~m} \\
8 \mathrm{~m}\end{array}$ & & & $\begin{array}{l}\text { Prop 0 } \\
\text { Piz }^{+} \text {Ergot } 0 \\
\text { Clon }^{+} \\
\text {Coprox }^{+}\end{array}$ \\
\hline $\begin{array}{l}12 \\
13\end{array}$ & $\begin{array}{l}36 \\
54\end{array}$ & $\begin{array}{l}F \\
F\end{array}$ & + & - & $\begin{array}{l}\mathrm{CH}-\mathrm{M} \\
\mathrm{CH}\end{array}$ & $\stackrel{\mathrm{CH}}{-}$ & $\underset{\mathrm{CH}}{\mathrm{ClM}}$ & - & $\begin{array}{l}\text { F, N, UL } \\
\text { UL, LL, C }\end{array}$ & $\begin{array}{r}3 y \\
10 y\end{array}$ & $\begin{array}{r}3 y \\
10 y\end{array}$ & $\begin{array}{l}\text { ly } 9 \mathrm{~m} \\
\text { ly } 4 \mathrm{~m}\end{array}$ & UL & & $\begin{array}{l}\text { Prop }^{+} \text {Ergot }^{+} \\
\text {Prop }^{++}{ }^{++} \text {Piz } 0 \\
\text { Coprox }^{+}\end{array}$ \\
\hline $\begin{array}{l}14 \\
15 \\
16\end{array}$ & $\begin{array}{l}27 \\
19 \\
37\end{array}$ & $\begin{array}{l}\mathbf{F} \\
\mathbf{F} \\
\mathbf{F}\end{array}$ & + & $\begin{array}{l}\text { ClM } \\
\text { CM } \\
\text { CM }\end{array}$ & $\begin{array}{l}\mathrm{ClM} \\
\mathrm{CH} \\
\mathrm{ClM}\end{array}$ & $\begin{array}{l}\mathrm{ClM} \\
\mathrm{CH} \\
\mathrm{ClM}\end{array}$ & $\frac{\mathrm{ClM}}{\overline{\mathrm{ClM}}}$ & $\begin{array}{l}\overline{C M} \\
\mathrm{CM}\end{array}$ & $\begin{array}{l}\text { N, UL, LL } \\
\text { F, N, UL } \\
\text { F, UL, LL, C, A }\end{array}$ & $\begin{array}{l}6 y \\
3 y \\
1 y\end{array}$ & $\begin{array}{l}6 \mathrm{y} \\
3 \mathrm{~m} \\
1 \mathrm{~m}\end{array}$ & $\begin{array}{l}8 \mathrm{~m} \\
3 \mathrm{~m} \\
1 \mathrm{y} 1 \mathrm{~m}\end{array}$ & $\begin{array}{l}\mathrm{N}, \mathrm{UL} \\
\text { UL } \\
\mathrm{F}, \mathrm{UL}, \mathrm{C}, \mathrm{A}, \mathrm{LL}\end{array}$ & UL & $\begin{array}{l}\text { Prop }{ }^{++} \\
\text {Prop 0 } \\
\text { Clon 0 } \\
\text { Aspirin }^{+}\end{array}$ \\
\hline 17 & 17 & $\mathbf{F}$ & & $\begin{array}{l}\mathrm{CM} \\
\mathrm{CH}\end{array}$ & $\mathrm{CH}$ & 一 & $\mathbf{C H}$ & - & UL, C & $3 y$ & ly & $2 \mathrm{y} 6 \mathrm{~m}$ & & & Prop + \\
\hline $\begin{array}{l}18 \\
19 \\
20 \\
21 \\
22\end{array}$ & $\begin{array}{l}13 \\
79 \\
19 \\
23 \\
37\end{array}$ & $\begin{array}{l}\mathbf{F} \\
\mathbf{F} \\
\mathbf{F} \\
\mathbf{F} \\
\mathbf{F}\end{array}$ & $\begin{array}{l}+ \\
+ \\
+ \\
+\end{array}$ & $\begin{array}{l}\overline{C H} \\
\mathrm{CM} \\
\overline{\mathrm{CM}}\end{array}$ & $\begin{array}{l}\mathrm{CH}-\mathrm{M} \\
\mathrm{CH} \\
\mathrm{CH}-\mathrm{M} \\
\mathrm{ClM} \\
\mathrm{CH}-\mathrm{M}\end{array}$ & $\begin{array}{l}\mathrm{CH}-\mathrm{M} \\
\mathrm{CH} \\
= \\
-\end{array}$ & $\begin{array}{l}\overline{\mathrm{CH}} \\
\overline{-} \\
\overline{\mathrm{ClM}} \\
\mathrm{CM}\end{array}$ & $\begin{array}{l}\overline{-} \\
\overline{\mathrm{CM}} \\
\overline{-}\end{array}$ & $\begin{array}{l}\text { UL } \\
\text { UL } \\
\text { N, UL } \\
\text { N, UL } \\
\text { N, UL }\end{array}$ & $\begin{array}{r}1 y \\
64 y \\
5 y \\
1 m \\
14 y\end{array}$ & $\begin{array}{l}1 \mathrm{y} \\
20 \mathrm{y} \\
1 \mathrm{y} 6 \mathrm{~m} \\
3 \mathrm{w} \\
1 \mathrm{~m}\end{array}$ & $\begin{array}{r}1 y \\
1 y \\
n \\
2 m \\
8 m \\
7 m\end{array}$ & UL & UL & $\begin{array}{l}\text { Prop 0, Piz } \text { Piz }^{++} \\
\text {Prop } \\
\text { Prop }^{+++} \\
\text {Prop } \\
\text { Pro }^{++}\end{array}$ \\
\hline
\end{tabular}

$\mathrm{FH}=$ Family History $\mathbf{C M}=$ Common Migraine; $\mathrm{ClM}=$ Classical Migraine; $\mathrm{CH}=$ Cluster Headache; $\mathrm{CH}-\mathrm{M}=\mathrm{Cluster}-\mathrm{migraine} ; \mathrm{F}=\mathrm{Face} ;$ $\mathbf{N}=$ Neck; UL = Upper Limb; $\mathbf{C}=$ Chest; $\mathbf{A}=$ Abdomen; $\mathbf{L L}=$ Lower Limb; $\mathbf{m}=$ months; $y=$ year; $\mathbf{w}=$ week; Par $=$ paracetamol; Prop = propanolol; Piz = pizotifen; Clon = clonidine; Ergot = ergotamine; Coprox = coproxamol.

${ }^{*}$ Had icepick headache ${ }^{96}$. Response to drugs: $0=$ nil; ${ }^{+}$and ${ }^{++}=$partial; ${ }^{++}=$good.

pain. Pain had a restricted localisation in 10 patients; to the wrist in five, to the ulnar or radial side of the forearm, to the fingers, to the little and ring fingers and to the thumb. It was confined just to the shoulder in one and just to the leg in another. Two cases had pain in one foot.

Case 7 Classical migraine in the past. Cluster headache with pain in arm and fingers, sparing the forearm. Since a teenager this 32 yr old woman had suffered from one or two episodes per year of right sided headache preceded by blurring of vision and "dancing images" and associated with nausea and vomiting. She had had none for the last 8 years. She presented with intermittent throbbing and stinging pain in the right eye, temple and ear, burning "numb" pain in the right arm and hand, specially ring and little fingers, and in the right side of the chest, for one year. Initially the episodes lasted from a few minutes to several hours, twice a week. Severe exacerbations appeared to be precipitated by bright light and in the morning and by sudden turning of the head. For the last 4 wk she had them daily. Following propranolol she improved. Over the following 4 months, she had slight pain in the right eye for 5 or 10 min on waking up every day and a lateralised headache the first day of her period. Over the next 7 months the pain in the right eye cleared but she noted intermittent tenderness in the right side of the head and a slight ache in the right arm. Wine triggered a sensation of "beating" below the right eye. In addition, she had a splitting right sided headache and a sharp pain in the right ear 7 days before her periods. Following Pizotifen she improved.

Often the pain affected more than one area and many combinations were seen. In 13 cases it spared intermediate areas between two parts of the limb and/or body. The neck and/or shoulder were spared in eight cases with pain in the face and/or ear and in the arm and in one case with pain in the neck and arm and forearm. The shoulder and arm were spared in one patient with pain in the axilla and forearm. The forearm was spared in four patients with pain in arm and hand. Both arm and forearm were spared in two cases with pain in the neck or shoulder and hand. The leg was spared in one case with pain in the knee and foot. 
Case 14 Classical migraine with associated or isolated upper limb pain sparing the forearm, pain in the leg, and ipsilateral weakness and paraesthesiae. This $27 \mathrm{yr}$ old woman had monthly throbbing headaches behind the eyes and in the vertex, preceded by flashing lights for twenty min, for $6 \mathrm{yr}$. They lasted from 3 to $24 \mathrm{~h}$, were associated with nausea, photophobia and difficulty focusing and were unrelated to her menses. For the same period she had separate episodes of pain and paraesthesiae in the right side of the neck and shoulder. Once they occurred daily for a week. For the last 8 months a dull pain had affected the right arm and hand and numbness and paraesthesiae in the right hand, particularly the thumb, for a few hours or most of the day, for 2-3 days, up to twice a week. During them the right arm felt weak. Similar pain in the right leg could sometimes be present during the attacks or occurred independently. Limb pain, weakness, numbness and paresthesiae had been associated with a headache similar to her attacks of migraine twice, but the latter had continued separately and unchanged, monthly, as before. Alcohol could trigger nausea and headache and trigger or exacerbate limb pain. The latter was also made worse by carrying heavy objects or during strenuous work.

Limb or body pain was throbbing, dull, shooting, boring, burning, soft or like pins. Triggering or exacerbating factors reported were limb use or movement, turning the head, bright lights, stress, cold weather, alcohol, touching or pressing the arm, and eating cheese or chocolate. It lasted seconds in two patients, less than $4 \mathrm{~min}$ in four, up to $2 \mathrm{~h}$ in nine, between 2 and $24 \mathrm{~h}$ in eight, and 3-4 days in three. There was insufficient data about duration in five cases. In 11 duration of limb pain varied between different episodes. The frequency of the episodes of limb pain could be established in 15 patients. It was less than one a day in three, daily in eight, one to four per week in five and once or twice per month in one. They occurred with clock-like regularity in three cases.

Sensory symptoms Nine patients had headache with paraesthesiae and/or numbness and ipsilateral limb pain. Their localisation is given in table 1. Sensory symptoms preceded limb pain in one case and followed it in another. In the remaining seven they occurred at the same time as limb pain.

Case 16 Classical migraine with ipsilateral, simultaneous, numbness and pain in the face, upper and lower limb, chest and abdomen. This $37 \mathrm{yr}$ old woman had had $3 \mathrm{~h}$ episodes of throbbing left or right sided occipito-temporal headaches for 1 yr, usually 2 days before her periods. In the last month she had two episodes of left sided headache, the first with intermittent numbness in the left thumb and radial aspect of the forearm for $2 \mathrm{~h}$, the second with numbness and pain in the left side of the face, left arm, left side of the chest and abdomen, lateral aspect of the left thigh and leg and dorsum of the left foot, which cleared by the following day. A minor headache persisted for a few hours further. Two days before seen she had pain in the left foot for $2 \mathrm{~h}$. Over the following
7 months she had intermittent left sided headaches as before, several times associated with pain and numbness in the left arm and leg, particularly wrist and ankle. Five months later she reported minor migraine episodes once a month with no associated symptoms and one further episode of pain in the left foot for several hours.

Episodes of paraesthesiae in isolation, with and without headache were seen in six cases. In five sensory symptoms occurred together with limb pain and without headache. In no case were they contralateral to limb pain or weakness. In the upper limb the hand was affected in eight, the arm in four, the forearm in two, the shoulder in one. Of those with involvement of the hand, three had them in all fingers, two in the thumb only and one in the thumb, index and middle fingers. The lower limb was affected below the knee twice and in all segments in one case.

Paraesthesiae in part of a limb or body area different from the one(s) with pain occurred in all but one case. There was complete spatial separation between them in five patients, three of whom had both symptoms simultaneously. In three cases either pain or paraesthesiae, exclusively, affected one body area, or part of it, but both symptoms involved other regions simultaneously.

Case 12 Cluster-migraine with spatial separation of simultaneous, ipsilateral, limb pain and paraesthesiae. Clock-like regularity. This $36 \mathrm{yr}$ old woman had intermittent bouts of daily severe right sided headache and pain in the right side of the neck and right arm for $3 \mathrm{yr}$. They lasted $3 \mathrm{~h}$ or until the following day. A recent bout had lasted $3 \mathrm{wk}$. She could wake up at 3 am with severe pain in the right ear which would build up, become throbbing and then spread to the right side of the head and neck, face, shoulder, arm and forearm, where it was of less intensity. She could then develop intermittent paraesthesiae in the right fingers which continued for some days, with or without the pain. The headache was associated sometimes with watering of the right eye and was increased by jolt. For the last 8 months she had soreness in the right side of the head, daily, and had had six intense exacerbations lasting a day each, during which she had to lie down and attempted to sleep. She felt some relief by holding her head with her hands and by rubbing the scalp. Her son suffered from migraine. She stopped eating cheese, started propranolol and two months later reported improvement. One year later she reported $1-2 \mathrm{~h}$ episodes of slightly painful numbness and paraesthesiae in the right arm associated with slight pain over the right side of the head about twice a month.

Weakness This affected the arm and/or leg concomitantly with limb pain in five patients. In one of them it also occurred independently from limb pain. Weakness preceded limb pain in one case. No case had weakness contralateral to limb pain.

A slow spread or march was described by three patients. One had weakness of the arm followed by numbness and paraesthesiae spreading from hand to elbow and then by pain from shoulder to arm over 
20 min. A second case reported a $30 \mathrm{~min}$ sequence from eye pain to lateralised pain in the nose, left arm and left leg. In the third, the pain moved from the occipital region and neck and localised to the shoulder and arm within a few minutes.

Case 5 Classical migraine in the past. Cluster headache and Cluster-migraine with ipsilateral pain and weakness in upper and lower limbs. Slow march of pain. Since the age of 40, a $52 \mathrm{yr}$ old man had suffered from 2 day episodes of occipital headache radiating forwards, every 6 months, associated with nausea and occasionally with flashing lights. He presented with a 2 month history of daily hourly episodes of deep pain in the left eye with sharp stabs and a feeling of blocked left nostril. Propranolol relieved the pain but it reappeared three days after it was stopped two weeks later, this time without stabbing components and with tenderness in the left side of the neck. Over the next 3 months the pain became less severe, localised to the left temple and left cheek, still with a feeling of blocked left nostril, lasted a full day, its frequency gradually diminished to once or twice a week and it was often associated with an ache in the left arm and leg. Over the next 3 months, on no treatment, the headache gradually became more severe and lasted 3-4 days, every $2 \mathrm{wks}$. It started again in the left eye, radiating to the left nose and jaw, with repeated intense exacerbations "like electric pulses" lasting seconds at a time. About $30 \mathrm{~min}$ into the episode he developed pain in the left arm and leg particularly shoulder, wrist and knee radiating to the dorsum of the left foot, and weakness in the left limbs; they lasted as long as the headache but occasionally a few hours more. Following Pizotifen he had three less severe episodes of headache but no limb pain or weakness.

The relation of limb pain with side of the headache was similar to that of sensory symptoms and weakness (table 2). Limb pain associated with both sensory symptoms and weakness was described by four patients, always ipsilaterally to both. The proportion of patients with face and lower limb involvement relative to the constant upper limb involvement was similar for pain, sensory symptoms and weakness (table 3).

Case 9 Classical migraine with associated or isolated, alternating, restricted, upper limb pain and weakness and paraesthesiae. Slow march. Since the age of $12 \mathrm{yr}$, this $25 \mathrm{yr}$ old woman had, every 2 months, right sided headaches and vomiting preceded by tinnitus and loss of vision. From the age of 19 the headaches had been more often left than right-sided, and localised particularly behind the eye and in the side of the neck. They were associated with ipsilateral or, sometimes, contralateral arm pain. Two weeks after the birth of a child, when aged 23 , she had headache and weakness in the right arm and leg for a few days. For the last year the attacks of headache had occurred for several days each time. A typical attack started with severe pain in the left (or right) eye spreading to the side of the head, dizziness, tinnitus, vomiting and impaired vision. The ipsilateral or, less often, contralateral arm would become weak for about $10 \mathrm{~min}$ and numbness and paraesthesiae spread in $2 \mathrm{~min}$ from the hand to the elbow and lasted for further $2 \mathrm{~min}$. Severe shooting pain radiating from the shoulder along the ulnar side of the arm to the elbow followed for $3-4 \mathrm{~min}$. The arm still felt heavy for another $15 \mathrm{~min}$. The headache usually cleared within $4 \mathrm{~h}$, but could last all day. It was made worse by stooping or turning the head quickly. The sensory symptoms and/or upper limb pain had also occurred without headache. On three occasions the headache had been preceded by an olfactory hallucination, with the smell of her grandfather's cigars or peanut butter. Her mother, sister and maternal grandparents had migraine. During a bout of pain in the left eye she had an injected conjunctiva and mild ptosis but no pupillary asymmetry; neurological examination was otherwise normal. Following propranolol $40 \mathrm{mg}$ thrice daily she improved.

Two cases reported minor swelling, and two bluish patches, in the skin of the painful limb.

Headache The types seen are shown in table 1. The features of the headache associated with limb pain appear in table 4 . Eleven patients also had current episodes of headache without limb pain. Ten of them had the same type of headache, whether or not it was associated with limb pain. The type of headache that was accompanied by limb pain did not change in 13 of 16 patients who had this association at follow up.

Table 2 Relation of limb pain, sensory symptoms and weakness to side of headache

\begin{tabular}{|c|c|c|c|c|c|c|}
\hline & \multicolumn{2}{|c|}{ Ipsilat } & \multicolumn{2}{|c|}{ Contralat } & \multicolumn{2}{|c|}{ Alternate } \\
\hline & $\bar{n}$ & $(\%)$ & $\bar{n}$ & $(\%)$ & $\bar{n}$ & $1 \%$ \\
\hline $\begin{array}{l}\text { Limb Pain } \\
\text { Paraesth/Numbness } \\
\text { Weakness }\end{array}$ & $\begin{array}{c}20^{*} \\
9 \\
6\end{array}$ & $\begin{array}{l}(100) \\
(100) \\
(100)\end{array}$ & $\begin{array}{l}3+ \\
1 \\
1\end{array}$ & $\begin{array}{l}(15) \\
(11) \\
(16)\end{array}$ & $\begin{array}{l}3+ \\
1+ \\
1\end{array}$ & $\begin{array}{l}(15) \\
(11)\end{array}$ \\
\hline
\end{tabular}

*Two patients (cases 14 and 20) had lateralised limb pain with non lateralised headache. $+=$ Cases $9,18,22 ; \ddagger=$ Cases $9,18,20$.

Table 3 Relative involvement of face, chest/abdomen and lower limb in patients with upper limb symptoms

\begin{tabular}{|c|c|c|c|c|c|c|c|c|c|}
\hline & \multirow[b]{2}{*}{$n$} & \multicolumn{2}{|c|}{ Face } & \multicolumn{2}{|c|}{ Chest/Abdom } & \multicolumn{2}{|c|}{$U$ Limb } & \multicolumn{2}{|c|}{ L Limb } \\
\hline & & $n$ & $\%$ & $n$ & $\%$ & $n$ & $\%$ & $n$ & $\%$ \\
\hline $\begin{array}{l}\text { Pain } \\
\text { Paraesth/Numbness } \\
\text { Weakness }\end{array}$ & $\begin{array}{r}22 \\
9 \\
6\end{array}$ & $\begin{array}{r}8 \\
4 \\
-\end{array}$ & $\begin{array}{l}36 \\
44 \\
\end{array}$ & $\begin{array}{r}4 \\
1 \\
-\end{array}$ & $\begin{array}{l}18 \\
11 \\
-\end{array}$ & $\begin{array}{r}22 \\
9 \\
6\end{array}$ & $\begin{array}{l}100 \\
100 \\
100\end{array}$ & $\begin{array}{l}7 \\
3 \\
2\end{array}$ & $\begin{array}{l}31 \\
33 \\
33\end{array}$ \\
\hline
\end{tabular}

See table 1 for details. $\mathrm{U}=$ upper; $\mathrm{L}=$ lower. 
Neurological Examination This was normal in all patients.

Investigations No significant abnormality was found in $x$-rays of the cervical spine $(\mathrm{n}=17)$, skull or sinuses $(n=16)$, chest $(n=12)$, and shoulder and/or upper $\operatorname{limb}(n=6)$, EEG $(n=13)$, cranial CT scan $(n=10)$, spinal and somatosensory $(n=9)$, visual $(n=6)$ and auditory $(n=4)$ evoked potentials, EMG and nerve conduction studies $(n=6)$, iv digital substraction angiography $(\mathrm{n}=3), \mathrm{CSF}$ examination $(\mathrm{n}=1)$, ECG $(n=6)$, echocardiography (1) and haematological and biochemical screening.

Treatment Seventeen out of 20 patients treated reported to have been helped by one or more of the drugs used (table 1).

\section{Discussion}

It is unlikely that the association between headache and limb pain was a chance finding. Limb pain occurred repeatedly with attacks of headache and behaved similarly to paraesthesiae and weakness, two accepted migraine accompaniments. The territories affected and the relative involvement of face, upper limb and lower limb were similar for pain and paraesthesiae. Involvement of the lower limb relative to the upper for pain and weakness was also similar. Limb pain was always ipsilateral to paraesthesiae and weakness. It was ipsilateral or contralateral to the headache, and alternated sides, in similar proportions to sensory symptoms and weakness.

Assuming that three-quarters of all local cases were referred to us, the association of upper limb pain with migraine and cluster headache had a minimum annual incidence of 3 per $10^{5}$ local residents and was seen in $1-2 \%$ of all new cases of headache attending our clinics. Lower limb pain had an incidence of 0.68 per $10^{5}$. The female/male ratio was $2 \cdot 8 / 1$.

Differential diagnosis No structural cause for headache and no entrapment lesions of the median and ulnar nerves nor lesions in the plexus or sensory roots were found. Cervical ribs were not seen. In two of three cases with upper limb minor unilateral swelling and/or blue patches limb pain alternated sides. Swelling of a limb has been reported in hemiplegic migraine. ${ }^{316}$ Cervical radiculopathy is unlikely because there was no cervical root pain, no motor, reflex or sensory signs, spondylotic change was infrequent and minor, there was lower limb (or body) pain, weakness and paraesthesiae and migrainous march. Upper limb pain was described in "cervical migraine", ${ }^{29} 30$ a controversial diagnosis ${ }^{36-38}$ not applicable to our cases since there was no history of cervical trauma nor radiculopathy. "Cervicogenic" headache, another controversial diagnosis, ${ }^{3739}$ is unlikely in the four patients whose symptoms were exacerbated by turning the head since they were not reproduced on examination and radiographs were normal.

Possible mechanisms for migrainous limb pain Upper limb pain below $\mathrm{C} 4$ distribution, and in the body and lower limb, argues against referred pain from trigeminal and/or upper cervical root distribution. No anatomical or physiological evidence of convergence of trigeminal and cervical afferents below $\mathrm{C} 4$ to the dorsal horns at $\mathrm{C} 1-\mathrm{C} 2$ levels was found in the cat ${ }^{4041}$

Table 4 Features of headache associated with limb pain

\begin{tabular}{|c|c|c|c|c|c|c|c|c|c|c|c|c|c|}
\hline \multirow[b]{2}{*}{ Type } & \multirow[b]{2}{*}{$n^{*}$} & \multicolumn{6}{|c|}{ Location $^{* *}$} & \multirow[b]{2}{*}{ Laterality } & \multirow[b]{2}{*}{ Course } & \multicolumn{3}{|l|}{ Focal symptoms } & \multirow[b]{2}{*}{ Others } \\
\hline & & Hemicr & Occ & $F / T / P$ & Eye & Ear. & Jaw/Face & & & Visual & Sensory & Weakness & \\
\hline $\mathrm{CM}$ & 4 & 3 & 0 & 2 & 0 & 1 & 2 & \multirow{2}{*}{$\begin{array}{l}\text { Left }=2 \\
\text { Right }=2 \\
\text { Left }=2 \\
\text { Alternate = } 3 \\
\text { Bilat =1 }\end{array}$} & Episodic & 0 & 0 & 0 & \multirow{4}{*}{$\begin{array}{l}\text { Nausea/Vom }=2 \\
\text { Blocked nose }=1 \\
\text { Nausea/Vom }=2 \\
\text { Photophobia }=2 \\
\text { Dizziness }=1 \\
\text { Olfact. Hallucin }=1 \\
\text { Nausea/Vom }=4 \\
\text { Blocked nose }=4 \\
\text { Lacrimation }=2 \\
\text { Dizziness }=1 \\
\text { Blocked nose }=2 \\
\text { Dizziness =1 }\end{array}$} \\
\hline $\mathrm{ClM}$ & 6 & 2 & 2 & 2 & 4 & 0 & 1 & & Episodic & $\begin{array}{l}\text { Bilat }=3 \\
\text { Hemianop }=1\end{array}$ & Unilat $=4$ & Unilat $=4$ & \\
\hline $\mathrm{CH}-\mathrm{M}$ & & 3 & 3 & 2 & 3 & 3 & 2 & $\begin{array}{l}\text { Left }=2 \\
\text { Right }=4 \\
\text { Alternate }=2 \\
\text { Bilat }=2+\end{array}$ & Bouts & Bilat $=2$ & Unilat $=4$ & Unilat $=3$ & \\
\hline $\mathrm{CH}$ & 7 & 4 & 1 & 3 & 4 & 2 & 3 & $\begin{array}{l}\text { Left }=4 \\
\text { Right }=2 \\
\text { Alternate }=1\end{array}$ & Bouts & 0 & 0 & 0 & \\
\hline
\end{tabular}

All types of headache with associated limb pain, at presentation or during follow up, are considered. Abbreviations for types of headache as in table 1 .

$\mathrm{n}=$ Number of patients. Hemicr $=$ hemicrania. $\mathbf{F} / \mathbf{T} / \mathbf{P}=$ frontal and/or temporal and/or parietal. Occ $=$ occipital.

* = Three cases had more than one type of headache with limb pain. Case 5 had both $\mathrm{CH}$ and $\mathrm{CH}-\mathrm{M}$. Case 3 had both $\mathrm{CH}-\mathrm{M}$ and $\mathrm{CM}$. Case 22 had CH-M, CIM and CM. ${ }^{* *}=$ More than one location was present in several patients.

$\dagger=$ In one the headache was also unilateral (alternating sides).

$\ddagger=$ In one case (15) paraesthesiae did not occur in association to headache with limb pain. 
but convergence for stimuli from the V, VII and X cranial nerves and 2 nd and 3rd sensory roots were found in the monkey. ${ }^{42}$

An epileptic mechanism for limb pain and headache seems unlikely. In most patients both were of prolonged duration and onset and termination were not sudden. Electroencephalography did not support this diagnosis. Epileptic headache is brief, 30 to $60 \mathrm{~s}$ in duration, and may be followed by head deviation, agitation, motor epileptic phenomena or alteration in consciousness, and epileptic limb pain is followed by motor seizures. ${ }^{4344}$

Some authors have supported a major role for the autonomic nervous system in the genesis of headache or limb pain based on anatomical or stimulation data ${ }^{74-49}$ or on the results of surgery. ${ }^{750-52}$ Others have presented evidence against such a role. ${ }^{913145354}$ The existence of afferent fibres travelling with the autonomic nervous system is currently accepted $^{5556}$ but not that they subserve pain sensation from the extremities. The surgical and stimulation studies in humans cited above and in the cat, ${ }^{57}$ can also be explained by the presence of somatic afferents that travel through the sympathetic trunk and rami to the sensory root ganglia. ${ }^{4958}$ Recent morphological and neurophysiological data in the cat ${ }^{58}$ do not support the idea that such spinal afferents are distributed in relation to blood vessels. ${ }^{49}$

A major peripheral autonomic mechanism for limb pain in this series is unlikely because (1) the type of pain (it was burning in only 1 case), (2) its distribution did not follow a vascular zone topography, ${ }^{59}$ (it was remarkably restricted in many cases and spared intermediate areas between two parts of a limb or between two parts of the body), (3) the lack of vasomotor, sudomotor and trophic phenomena, and (4) the associated paraesthesiae and weakness in the absence of peripheral lesions.

Could limb or body pain result primarily from dysfunction of structures within the CNS?60-62 The following considerations support a central origin for limb and body pain. (1) It did not follow a segmental peripheral distribution. In many patients the pain had a very restricted localisation. In others, it was more diffuse and affected the trunk and lower limb or all one side, (2) the character of the pain, the triggering factors in many (particularly limb movement and touching or pressing the limb) and the vasomotor phenomena in a few, have all been described in central pain, ${ }^{60-62}$ (3) it was frequently associated with ipsilateral paraesthesiae and weakness. Paraesthesiae affected the same areas, but did not always involve the same part, of the limb where the pain was perceived. (4) It was unilateral but did alternate sides. (5) It involved predominantly the upper limb and face, both areas with extensive central representation. (6) Three patients reported a slow migrainous march. ${ }^{63-65}$

Possible central sites mediating migrainous limb pain Central pain originating in the spinal cord and brain-stem may be unilateral but bilateral symptoms and signs, including crossed syndromes, are seen. ${ }^{60616667}$ Our patients did not have, in any attack, paraesthesiae or weakness bilaterally nor limb pain contralateral to paraesthesiae and weakness. One had pain in one or both arms simultaneously. A patient with bilateral arm pain exacerbated by movement who had bilateral occipitoparietal lesions has been recorded. ${ }^{68}$

It may be impossible to distinguish cortical from subcortical or thalamic lesions by the topography and features of the pain ${ }^{60-6267}$ but both the migrainous march and the very focal nature of the pain in several patients may suggest that more anatomical resolution than that present in the thalamus is necessary. Although there is morphological evidence ${ }^{69}$ of a topical order of distribution of spinothalamic fibres in the monkey's nucleus ventralis posterior lateralis, which projects to cortex (SI and SII), electrophysiological recordings suggest that this distribution does not result in a strict somatotopic representation. Neurons responsive to noxious stimuli are also found in the medial and intralaminar nuclei but they have large, often bilateral, receptive fields with no encoding of stimulus parameters. ${ }^{70} 71$

There is evidence for a role of the cortex in central pain although Penfield and Boldrey rarely evoked it by electrical stimulation. ${ }^{72}$ Limb pain has been described as an aura or part of focal epileptic? attacks. ${ }^{4373} \mathrm{~A}$ variety of lesions affecting the parietal region and involving SI or SII areas or their projections in patients with epileptic or nonepileptic contralateral limb pain are recorded. ${ }^{4374-80}$ Such pain may be relieved by removal of the lesion. ${ }^{81}$ Phantom limb pain was reproduced in remarkably localised areas of the hand, arm, leg and foot by stimulation of the contralateral postcentral and supplementary sensory cortex ${ }^{82}$ Finally, stimulation of the tooth pulp, mediated by A-delta and C fibres, thought to subserve nociceptive information, evoked responses in the contralateral lower postcentral region. ${ }^{83}$ There is also experimental evidence for a role of the parietal cortex in nociception. ${ }^{84}$ In the monkey, some SI and SII neurons respond to nociceptive stimuli and have large receptive fields. ${ }^{85-87} \mathrm{~A}$ more selective nociceptive projection appears to exist in the floor of the central sulcus (Brodmann area 3a) where there are neurons that respond to a single contralateral tooth pulp stimulation. ${ }^{88}$ Connections between SI and SII and between SII and the ipsilateral motor cortex are described in the monkey. 89

Some of the restricted localisations of pain reported 
in unilateral painful epileptic seizures closely resemble those in our patients. Pain in the face and trunk, ${ }^{90}$ nose and eye, face, shoulder and arm and retroauricular region, ${ }^{43}$ hand and foot, ${ }^{7580}$ thumb or big toe $^{91}$ are all mentioned. Pain in seizures is often associated with ipsilateral paraesthesiae or motor phenomena which may, or may not, affect the same areas as the pain. It has been proposed that the probable sites of origin of the electrical discharges in painful seizures were the contralateral SI and SII areas and that decreased inhibition accompanying seizures interferes with cortical pain control mechanisms. ${ }^{43}$ Migraine may be another mechanism which disturbs, temporarily, cortical or thalamocortical processes involved in pain. Ischaemia or spreading depression, ${ }^{2464}$ or both, may relate to such cortical or thalamocortical dysfunction. Regional cerebral blood flow studies showed marked posterior oligaemia at the time of an attack of headache in a man with migraine and attacks of pain in the right arm without detectable organic explanation. ${ }^{24}$

\section{Implications for possible mechanisms of} headache Limb pain, sensory symptoms and weakness were always on the same side. They were ipsilateral to the headache in 20 of our patients but none was exclusively contralateral. Paraesthesiae and weakness were often ipsilateral to migraine headache in three series. ${ }^{92-94}$

Headache may have a central origin. On stimulation of the sensorimotor cortex 6 responses of head pain out of 11 responses of head sensation were recorded, two contralateral, three ipsilateral and one unknown, but no cortical maps were made of this group. ${ }^{72}$ With a stereotactic technique designed to reach fibres between thalamus and parietal cortex, particularly SII, pain was reproduced by stimulating this region in one case of "atypical facial neuralgia" (No 7) and improved in this and in a similar case (No 8) with a destructive lesion. ${ }^{95}$ Unilateral headache at the onset of seizures is recognised. ${ }^{4373}$ It has been associated with ipsilateral visual or motor symptoms but there was no relationship between the site of epileptic discharges and the location of head pain when the latter was the initial symptom. ${ }^{43}$

Whether a generalised vasomotor disturbance mediates focal symptoms, intracerebrally, in one side and headache extracerebrally in the other side, or whether headache, limb pain, paraesthesiae and weakness all have a primary neurogenic, or vascular, central origin is not clear. The slow march of pain from the head to the limbs supports a similar central origin in some cases but it is not possible to exclude from our data that more than one mechanism may operate in migraine headache.

We thank Dr F B Gibberd for helpful criticism.

\section{References}

1 Liveing E. On Megrim, Sick-headache and Allied Disorders: A Contribution to the Pathology of Nerve-Storms. London: Churchill, 1873.

2 Gowers WR. A Manual of Diseases of the Nervous System. Philadelphia: Blakiston, 1888:1176-7.

3 Jeliffe SE. Aphasia, hemiparesis and hemianaesthaesia in migraine. NY Med J 1906;83:33-36.

4 Sluder G. The anatomical and clinical relations of the sphenopalatine (Meckel's) ganglion to the nose and its accessory sinuses. NY Med J 1909;88:293-8.

5 Sluder G. The syndrome of sphenopalatine-ganglion neurosis. Am J Med Sci 1910;140:868-78.

6 Sluder G. Etiology, diagnosis, prognosis and treatment of sphenopalatine ganglion neuralgia. JAMA 1913;61:1201-6.

7 Sluder G. Hyperplastic sphenoiditis: and its clinical relations to the second, third, fourth, fifth, sixth and vidian nerves and nasal ganglion. Trans Am Laryngol Assoc 1915a;37:215-42.

8 Sluder G. The Sympathetic Syndrome of Sphenopalatine or Nasal Ganglion Neurosis: together with a Consideration of the Neuralgic Syndrome: and their Treatment. Trans Am Laryngol Assoc 1915b;37:243-62.

9 Cushing $\mathrm{H}$. The major trigeminal neuralgias and their surgical treatment based on experiences with 332 Gasserian operations. Am J Med Sci 1920;160:157-84.

10 Harris W. Neuritis and Neuralgia. Oxford: Oxford University Press, 1926.

11 Vail HH. Vidian neuralgia from disease of the sphenoidal sinus. Report of a case. Arch Surg 1929;18:1247-55.

12 Vail HH. Vidian neuralgia. Ann Otol Rhinol Laryngol 1932:41:837-56

13 Glaser MA. Atypical neuralgia, so called: a critical analysis of one hundred and forty-three cases. Arch Neurol Psychiatry 1928;20:537-58.

14 Frazier $\mathrm{CH}$. Atypical Neuralgia. Unsuccessful attempts to relieve patients by operations on the cervical sympathetic system. Arch Neurol Psychiatry 1928;19:650-9.

15 Brunelli MA. Migraine et sympathalgia homolaterale de l'hemicorp. Rev Neurol (Paris) 1937;68:167-9.

16 Montgomery BM, King WW. Hemiplegic Migraine. A case with paroxysmal shoulder-hand syndrome. Ann Int Med 1962;57:450-5.

17 Wolff HG. Headache and other Head Pain. 2nd ed. New York: Oxford University Press, 1963: Chapter 15.

18 Sacks OW. Migraine. London: Faber and Faber, 1970: Chapter 1.

19 Sutherland JM, Eadie MJ. Cluster Headache. In: Friedman AP, ed. Research and Clinical Studies in Headache. An International Review, Volume 3. Basel: Karger, 1972:92-125.

20 Wakefield G. Clinical Features of Migraine with special reference to the migraine aura. In: Pearce J, ed. Modern Topics in Migraine. London: W Heinemann, 1975:22-29.

21 Leon-Sotomayor LA. Cardiac migraine. Report of twelve cases. Angiology 1974;25:161-71.

22 Sjaastad O, Dale I. Evidence for a new (?) treatable headache entity. Headache 1974;14:105-8.

23 Sjaastad O, Dale I. A new (?) clinical headache entity "chronic paroxysmal hemicrania" 2. Acta Neurol Scand 1976;54:140-59.

24 Olesen J, Larsen B, Lauritzen M. Focal Hyperemia followed by spreading oligemia and impaired activation of rCBF in classical migraine. Ann Neurol 1981;9:344-52.

25 Bruyn GW. Complicated Migraine. In: Vinken PJ, Bruyn GW, eds. Headaches and Chronic Neuralgias. Handbook of Clinical Neurology, Volume 5. Amsterdam: Elsevier Science Publishers, 1968:59-95.

26 Bruyn GW. Migraine equivalents. In: Vinken PJ, Bruyn GW, Klawans HL, Rose FC, eds. Handbook of Clinical Neurology, Volume 4(48). Amsterdam: Elsevier Science Publishers, 1986:155-71.

27 Lance J. Mechanisms and management of headache. 4th ed. London: Butterworth and Co, 1982. 
28 Walton J. Brain's Diseases of the Nervous System, 9th ed. Oxford: Oxford University Press, 1985.

29 Bartschi-Rochaix W. Migraine Cervicale (Das encephale Syndrom nach Halswirbeltrauma). Bern: Verlag Hans Huber, 1949:29-31.

30 Bartschi-Rochaix W. Headaches of cervical origin. In: Vinken PJ, Bruyn GW, eds. Handbook of Clinical Neurology, Volume 5. Amsterdam: North-Holland Publishing Co, 1968:192-203.

31 Ad Hoc Committee on Classification of Headache. Classification of Headache. JAMA 1962:717-718.

32 Rose FC. Headache: definitions and classification. In: Vinken PJ, Bruyn GW, Klawans HL, Rose FC, eds. Handbook of Clinical Neurology, Volume 4(48). Amsterdam: Elsevier Science Publishers, 1986:1-12.

33 World Federation of Neurology. Meeting of the Research Group on Migraine and Headache. J Neurol Sci 1969:9:202.

34 Harris W. Ciliary (migrainous) neuralgia and its treatment. $\mathrm{Br}$ Med J 1936a;1:457-60.

35 Solomon S. Variants of Cluster Headache. In: Vinken PJ, Bruyn GW, Klawans HL, Rose FC, eds. Handbook of Clinical Neurology, Volume 4(48). Amsterdam: Elsevier Sciences Publishers, 1986:267-71.

36 Edmeads $\mathrm{J}$. Headaches and head pains associated with diseases of the cervical spine. Medical Clinics of North America 1978;62:533-44.

37 Sjaastad O, Saunte C, Hovdahl H, Breivik H, Gronbaek E. "Cervicogenic" headache. An hypothesis. Cephalalgia 1983;3:249-56.

38 Berger M, Gerstenbrand F. Cervicogenic headache. In: Vinken PJ, Bruyn GW, Klawans HL, Rose FC, eds. Handbook of Clinical Neurology, Volume 4(48). Amsterdam: Elsevier Science Publishers, 1986:405-412.

39 Bogduk N. Headaches and the cervical spine. Cephalalgia 1984;4:7-8.

40 Kerr FWL, Olafsson R. Trigeminal and cervical volleys. Arch Neurol Chicago 1961;5:171-78.

41 Kerr FWL. Central relationships of trigeminal and cervical primary afferents in the spinal cord and medulla. Brain Res 1972;73:561-72.

42 Denny-Brown D, Yanagisawa N. The function of the descending root of the fifth nerve. Brain 1973;96:783-814.

43 Young GB, Blume WT. Painful epileptic seizures. Brain 1983;106:537-54

44 Laplante P, Saint-Hilaire JH, Bouvier G. Headache as an epileptic manifestation. Neurology 1983;33:1493-5.

45 Vail HH. Pathways of Reflex Pain in Vidian Neuralgia. Arch Otolaryngol 1935;21:277-84.

46 Harris $W$. The role of the sympathetic in sensory conduction and certain neuralgias. $\mathrm{Br}$ Med $J$ 1936b;2:112-5.

47 Walker AE, Nulson F. Electrical stimulation of the upper thoracic portion of the sympathetic chain in man. Arch Neurol Psychiatry 1948;59:559-60.

48 Echlin F. Pain response of stimulation of the lumbar sympathetic chain under local anaesthesia. $J$ Neurosurg 1949;6:530-3.

49 Kuntz A. Afferent innervation of peripheral blood vessels through sympathetic trunks. Its clinical implications. South Med J 1951;44:673-8.

50 Fay T. Atypical Neuralgia. Arch Neurol Psychiatry 1927;18:309-13.

51 Fay T. Atypical facial neuralgia, a syndrome of vascular pain. Ann Oto Rhinol Laryngol 1932;41:1030-62.

52 Braeucker W. Die Anatomie und Chirurgie des Vegetativen Nervensystems. Dsche Z Nervenheilkunde 1928;106:163-71.

53 Frazier $\mathrm{CH}$, Russell EC. Neuralgia of the face. An analysis of 754 cases with relation to pain and other sensory phenomena before and after operation. Arch Neurol Psychiatry 1924;11:557-63.

54 White JC, Sweet WH. Cephalic Pain-Transmission pathways uncertain. In: White JC, Sweet WH, eds. Pain. Its Mechanisms and Neurosurgical Control. Springfield: Charles C Thomas, 1955:494-542.
55 Pick. The Autonomic Nervous System. Philadelphia: JB Lippincott, 1979: Chapters 2 and 19.

56 Williams PL, Warwick R. Gray's Anatomy, 36th ed. London: Churchill-Livingstone, 1980.

57 Davis L, Pollock CJ. The role of the sympathetic nervous system in the production of pain in the head. Arch Neurol Psychiatry 1932;27:282-93.

58 Janig W, Kollmann W. The involvement of the sympathetic nervous system in pain. Possible neuronal mechanisms. Arzneimittel Forschung 1984;34:1051-114.

59 Gross D. Pain and autonomic nervous system. Adv Neurol 1974;4:93-103.

60 Riddoch G. Clinical features of central pain. Lance 1938;i:1093-8.

61 Riddoch G. Clinical features of central pain. Lancet 1938;i:1150-6.

62 Riddoch G. Clinical features of central pain. Lancet 1938;i:1205-9.

63 Gowers WR. The Borderland of Epilepsy. London: Churchill, 1907:79-80.

64 Basser LS. The relation of migraine and epilepsy. Brain 1969;92:285-300.

65 Fisher CM. Late-life migraine accompaniments as a cause of unexplained transient ischaemic attacks. Can $\mathrm{J}$ Neurol $\mathrm{Sc}$ 1980;7:9-17.

66 Kendall D. Some observations on central pain. Brain 1939;62:253-73.

67 Pagni CA. Central pain due to spinal cord and brainstem damage. In: Wall P, Melzack R, eds. Pain. London: ChurchillLivingstone, 1984:481-495.

68 Guillain G, Bertrand L. La necrose atrophique symetrique de circonvolutions parietales ascendantes et des convolutions occipitales. Forme anatomo-clinique encephalique des ischemies necrotiques symetriques des extremites. Ann Med 1932;31:35-58.

69 Mehler WR, Feferman ME, Nauta WJH. Ascending axon degeneration following anterolateral cordotomy. An experimental study in the monkey. Brain 1960;83:718-50.

70 Yasksh TL, Hammond DL. Peripheral and central substrates involved in the rostral transmission of nociceptive information Pain 1982;13:1-85.

71 Guilbaud G, Peschanski M, Besson J-M. Experimental data related to nociception and pain at the supraspinal level. In: Wall P, Melzack R, eds. Pain. London: Churchill-Livingstone 1984:110-118.

72 Penfield W, Boldrey E. Somatic motor and sensory representations in cerebral cortex of man as studied by electrical stimulation. Brain 1937;60:389-443.

73 Gowers WR. Epilepsy and other Chronic Convulsive Diseases. Their Causes, Symptoms and Treatment. London: Churchill, 1881:59.

74 Schuster P. Beitrage zur Pathologie des Thalamus opticus. Arch Psychiatrie NervenKrankheiten 1936;105:550-622.

75 Michelsen JJ. Subjective disturbance of the sense of pain from lesions of the cerebral cortex. Research Publications: Assoc Res Nerv Ment Dis 1943;23:86-99.

76 Biemond A. The conduction of pain above the level of the thalamus opticus. Arch Neurol Psychiatry 1956;75:231-44.

77 Silver ML. "Central pain" from cerebral arteriovenous aneurysm. J Neurosurg 1957;14:92-97.

78 Davison CL, Schick W. Spontaneous pain and other subjective sensory disturbances. Arch Neurol Psychiatry 1935;34:1204-37.

79 Wilkinson HA. Epileptic pain. An uncommon manifestation with localising value. Neurology 1973;23:518-20.

80 Fields HL, Adams JE. Pain after cortical injury relieved by electrical stimulation of the internal capsule. Brain 1974;97:169-78.

81 Sweet WH. Cerebral localization of pain. In: Thompson RD, Green JR, eds. New perspectives in Cerebral Localization. New York: Raven Press, 1982:205-242.

82 Woolsey CN, Erickson TS, Gibson WE. Localisation in somatic sensory and motor areas of human cerebral cortex as deter- 
mined by direct recording of evoked potentials and electrical stimulation. $J$ Neurosurg 1979;51:476-506.

83 Chatrian GE, Canfield RC, Knauss TA, Lettich E. Central responses to electrical tooth pulp stimulation in man. Neurology 1975;25:745-57.

84 Andersson SA, Rydenhag B. Cortical nociceptive systems Phil Trans $R$ Soc London 1985;B308:347-55.

85 Mountcastle VB, Powell TPS. Neural mechanisms subserving cutaneous sensibility with special reference to the role of afferent inhibition in sensory perception and discrimination. Bull Johns Hopkins Hospital 1959;105:201-32.

86 Kenshalo DR, Isensee O. Response of primate SI cortical neurons to noxious stimuli. 10th Annual meeting, Cincinnati. Neurosc Abst 1980;6:245.

87 Whitsel BL, Petrucelli LM, Werner G. Symmetry and connectivity in the map of the body surface in somatosensory area II of primates. J Neurophysiol 1969;32:170-83.

88 Biedenbach MA, Van Hassel HJ, Brown AC. Tooth pulp driven neurons in somatosensory cortex of primates: role in pain mechanisms including a review of the literature. Pain
1979;7:31-50.

89 Jones EG, Powell TPS. Conexions of the somatic sensory cortex of the rhesus monkey. I. -Ipsilateral cortical conexions. Brain 1969;92:477-502.

90 Mann L. Ein Unge Wohnlicher Fall Von Traumatischer Spatepilepsie Mit Sensibler Neuralgiformer Aura, Encephalographisch Nachgewiesen. Klin Wochenschr 1930;9:218-20.

91 Foerster O. Sensible Corticale Felder. In: Bumke O, Foerster O, eds. Handbuch der Neurologie, Volume 6. Berlin: Julius Springer, 1936:358-449.

92 Bradshaw P, Parsons M. Hemiplegic Migraine, a Clinical Study. Q J Med, New Series 1965;XXXIV(133):65-85.

93 Bruyn GW, Weenwick HR. Migraine Accompagnee. A Critical Evaluation. Headache 1966;6:1-22.

94 Peatfield RC, Gawel MJ, Rose FC. Asymmetry of aura and pain in migraine. J Neurol Neurosurg Psychiatry 1981;44:886-88.

95 Talairach J, Tournoux P, Bancaud J, Chirurgie parietale de la douleur. Acta Neurochirurg (Wien) 1960;8:153-250.

96 Raskin NH, Schwartz RK. Icepick-like pain. Neurology 1980;30:203-5. 